\title{
Light responses in the mouse retina are prolonged upon targeted deletion of the HCN1 channel gene
}

\author{
Gabriel C. Knop, ${ }^{1, *,+}$ Mathias W. Seeliger ${ }^{2,+}$ Frank Thiel, ${ }^{1}$ Anja Mataruga, ${ }^{1}$ U. Benjamin Kaupp, ${ }^{1, \dagger}$ \\ Christoph Friedburg, ${ }^{3}$ Naoyuki Tanimoto ${ }^{2}$ and Frank Müller ${ }^{1}$ \\ ${ }^{1}$ Institut für Neurowissenschaften und Biophysik (INB-1), Forschungszentrum Jülich, Leo-Brandt-Strasse, D-52425 Jülich, Germany \\ ${ }^{2}$ Ocular Neurodegeneration Research Group, Institute for Ophthalmic Research, Centre for Ophthalmology, Eberhard-Karls \\ University, Tübingen, Germany \\ ${ }^{3}$ Department of Ophthalmology, University Hospital Giessen and Marburg, Giessen, Germany
}

Keywords: electrophysiology, electroretinography, ERG, HCN channels, Ih, retina

\begin{abstract}
Hyperpolarization-activated and cyclic nucleotide-gated ( $\mathrm{HCN})$ channels contribute to pacemaker activity, and co-determine the integrative behaviour of neurons and shape their response to synaptic stimulation. Four channel isoforms, HCN1-4, have been described in mammals. Recent studies showed particularly strong expression of HCN1 channels in rods and cones of the rat retina, suggesting that HCN1 channels are involved in the shaping of light responses in both types of photoreceptors. Therefore, the loss of HCN1 channels should lead to pronounced changes in light-induced electrical responses under both scotopic and photopic conditions. This was tested using a mouse transgenic approach. We used immunohistochemistry and patch-clamp recording to study the distribution of HCN1 channels in the mouse retina. HCN1 channels were strongly expressed in rod and cone photoreceptors, as well as in some bipolar, amacrine and ganglion cell types. In electroretinograms (ERGs) from animals in which the HCN1 channel gene had been knocked out, the b-wave amplitudes were unaltered (scotopic conditions) or somewhat reduced (photopic conditions), whereas the duration of both scotopic and photopic ERG responses was strikingly prolonged. Our data suggest that in visual information processing, shortening and shaping of light responses by activation of HCN1 at the level of the photoreceptors is an important step in both scotopic and photopic pathways.
\end{abstract}

\section{Introduction}

In the mammalian retina, the light response of photoreceptors is processed by an elaborate neuronal network [for review, see Wässle \& Boycott (1991) and Masland (2001)]. The photoreceptors, rods and cones, are depolarized in the dark, but hyperpolarize upon illumination. At least 10 types of cone bipolar cells and one type of rod bipolar cell provide the pathways for the signal flow from photoreceptors to ganglion cells, the output neurons of the retina [for the rat, see Euler \& Wässle (1995), Hartveit (1997) and Ivanova \& Müller (2006); for the mouse, see Ghosh et al. (2004) and Pignatelli \& Strettoi (2004)]. Along the way from photoreceptors to ganglion cells, cellular signals are shaped by two principal mechanisms: (i) lateral inhibition within the neuronal network involving feedforward and feedback mechanisms; and (ii) shaping of voltage responses by the kinetic properties

Correspondence: Dr F. Müller, as above.

E-mail: f.mueller@fz-juelich.de

* Present address: Institut für Biologie und Umweltwissenschaften, AG Neurobiologie, Carl-von-Ossietzky-Universität Oldenburg, 26111 Oldenburg, Germany.

${ }^{\dagger}$ Present address: Research Center Caesar, Friedensplatz 16, 53111 Bonn, Germany.

${ }^{\ddagger}$ G.K. and M.S. contributed equally to this work.

Received 3 July 2008, revised 11 September 2008, accepted 24 September 2008 of the ion channels involved in the generation and propagation of electrical signals. One family of voltage-gated channels present in the retina are the hyperpolarization-activated and cyclic nucleotide-gated (HCN) channels. HCN channels co-determine the resting potential and membrane conductance, and thereby play an important role in the integrative behaviour of neurons and the sensitivity to synaptic input. HCN channels affect the cable properties of dendrites and shape the time course and propagation of excitatory and inhibitory postsynaptic potentials (Magee, 1998); for reviews, see Pape (1996) and Robinson \& Siegelbaum (2003).

In rod and cone photoreceptors, HCN channels were suggested to shape the light response (Fain et al., 1978; Baylor et al., 1984; Hestrin, 1987). HCN channels become activated during hyperpolarization in bright light and depolarize the cell towards the dark membrane potential, making the light response transient.

In mammals, four channel genes (HCN1-4) have been identified (Ludwig et al., 1998, 1999; Santoro et al., 1998; Seifert et al., 1999); for a review, see Kaupp \& Seifert (2001). We have previously shown that $\mathrm{HCN}$ channel isoforms are differentially expressed in the rat retina (Müller et al., 2003; Ivanova \& Müller, 2006). HCN1 was the most abundant isoform, being expressed throughout all cell classes of the retina. Particularly strong expression was observed in both rod and 
cone photoreceptors, suggesting that $\mathrm{HCN} 1$ plays an important role in the shaping of retinal light responses. Here, we studied the expression and functional properties of HCN1 channels in photoreceptors and bipolar cells of the mouse retina. By recording scotopic and photopic light responses in normal mice and in HCN1 knock-out mice, we showed that HCN1 channels shorten retinal light responses in both rod and cone pathways.

\section{Materials and methods}

All experimental procedures were approved by the local animal care committee of the Forschungszentrum Jülich (Tierschutzbeauftragte) and were in accordance with the law of animal experimentation issued by the German Government (Tierschutzgesetz).

\section{Immunohistochemistry}

Adult mice (C57Bl/6; Elevage Janvier, France) were deeply anaesthetized with isoflurane, and decapitated. Eyes were enucleated and opened by an encircling cut at the limbus. The retinae in the eyecup were immersion-fixed for $30 \mathrm{~min}$ in $4 \%$ paraformaldehyde in $0.1 \mathrm{M}$ phosphate buffer ( $\mathrm{PB}, \mathrm{pH}$ 7.4) at room temperature, and washed in $\mathrm{PB}$ several times. Tissue was incubated in $10 \%$ sucrose in $\mathrm{PB}$ for $1 \mathrm{~h}$, and then in $30 \%$ sucrose at $4{ }^{\circ} \mathrm{C}$ overnight. The retina was flat-embedded and frozen in optimal cutting temperature compound. Twentymicrometre-thick vertical sections were cut on a cryostat and collected on Superfrost Plus slides. Sections were incubated overnight with primary antibodies diluted in 5\% chemiblocker (Chemicon, Hofheim, Germany), $0.5 \%$ Triton $\mathrm{X}-100$, and $0.05 \% \mathrm{NaN}_{3}$ in PB. Sections were washed in PB and incubated in secondary antibodies diluted in 5\% chemiblocker and $0.5 \%$ Triton X-100 in PB for $1 \mathrm{~h}$, washed in PB, and coverslipped with Aqua Polymount (Polysciences, Eppelheim, Germany). Sections were examined with a Leica TCS confocal laser scanning microscope (Leica Microsystems, Germany) with $63 \times / 1.32$ oil immersion lenses. Images were processed and printed with ADOBE Рнотоsнор. For double labelling, primary antibodies were mixed and applied simultaneously. All secondary antibodies were highly crossabsorbed and were carefully tested to exclude reactions with the wrong primary antibody. Concentrations of the antibodies, laser intensity and filter settings were carefully controlled, and the sequential scanning mode was employed to completely rule out cross-talk between the fluorescence detection channels. Bandpass filters of 500-530 nm for green fluorescence (Alexa488), $580-650 \mathrm{~nm}$ for red fluorescence (Cy3), and 680-750 nm for infrared fluorescence (Cy5) were used.

\section{Primary antibodies}

The primary antibodies used were: RTQ-7C3 (F. Müller, Forschungszeutrum Jülich, Germany) [rat, HCN1 (Müller et al., 2003)], $1: 20$; anti-HCN1 (rabbit; Alomone, Jerusalem, Israel), 1 : 200-400; CabP5 (F. Haeseleer, Dep. Ophtalmology, Seattle, WA, USA) [rabbit (Haeseleer et al., 2000)], $1: 800-1600 ;$ HCN4 $\gamma$ (F. Müller, Forschungszeutrum Jülich, Germany) [guinea pig (Mataruga et al., 2007)], 1 : 1000; PKARII $\beta$ (mouse, against protein kinase A; BD Biosciences, San Jose, CA, USA), 1 : 4000; and PKC $\alpha$ (mouse; BD Biosciences), $1: 50$. The specificity of $\mathrm{HCN} 1$ antibodies was ensured by the following criteria: first, antibodies recognized protein bands of the expected molecular mass of $102 \mathrm{kDa}$ in western blots of proteins from mouse retina and from HEK cells expressing mouse $\mathrm{HCN} 1$; second, if both HCN1 antibodies were applied to the same section in double labelling experiments, identical structures were stained; and third, no staining was observed in retinae of HCN1 knock-out animals.

\section{Secondary antibodies}

The secondary antibodies used were goat anti-rabbit Alexa488, goat anti-rat Alexa488 (both 1:500; Invitrogen, Karlsruhe, Germany), donkey anti-rabbit $\mathrm{Cy} 3$, donkey anti-mouse $\mathrm{Cy} 3$, donkey anti-guinea pig Cy3 (all 1 : 500; Dianova, Hamburg, Germany), and donkey antimouse Cy5 (1: 100, Dianova, Germany).

\section{Patch-clamp electrophysiology}

Adult mice were deeply anaesthetized with isoflurane and decapitated. Retinae were dissected free in oxygenized Hank's balanced salt solution and mounted onto a millipore filter (NC10; Schleicher and Schuell, Germany). Slices of thickness $150 \mu \mathrm{m}$ were cut in a custommade device. Recordings were done at room temperature with an Axopatch-200A amplifier and PCLAMP6 software (Molecular Devices, Sunnyvale, USA). The recording chamber was perfused with an oxygenized solution containing: $137 \mathrm{mM} \mathrm{NaCl}, 5.4 \mathrm{mM} \mathrm{KCl}, 1.25 \mathrm{mM}$

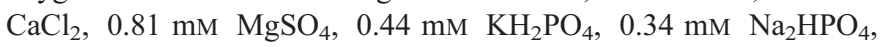
$10 \mathrm{~mm}$ Hepes, $5.6 \mathrm{~mm}$ glucose, and $0.031 \mathrm{~mm}$ phenol red (pH 7.4). The intracellular solution contained: $126 \mathrm{~mm}$ potassium gluconate, $4 \mathrm{~mm} \mathrm{KCl}, 10 \mathrm{~mm} \mathrm{NaCl}, 1 \mathrm{~mm} \mathrm{CaCl} 2,1 \mathrm{~mm} \mathrm{MgCl}_{2}, 10 \mathrm{~mm}$ EGTA, $10 \mathrm{~mm}$ Hepes, $1 \mathrm{~mm}$ MgATP, $1 \mathrm{~mm} \mathrm{Na} \mathrm{GTP}_{3}, 0.008 \%$ Lucifer Yellow, and $0.4 \%$ biocytin $(\mathrm{pH} 7.3)$. All substances were purchased from Sigma (München, Germany). Pipette resistances ranged from 7 to $9 \mathrm{M} \Omega$, seal resistances were $>3 \mathrm{G} \Omega$, and input resistances of cells were at least $1 \mathrm{G} \Omega$. Cells were voltage-clamped with the patch-clamp technique in the whole cell mode. The membrane potential $\left(V_{\mathrm{m}}\right)$ of the cells was clamped to a holding value of $-60 \mathrm{mV}$ (which was close to the resting potential of most bipolar cells and did not activate other voltage-gated channels), and HCN currents were recorded during families of hyperpolarizing steps $(-60 \mathrm{mV}$ to $-135 \mathrm{mV}, 15 \mathrm{mV}$ increments). At $V_{\mathrm{m}}=-60 \mathrm{mV}$, some $\mathrm{HCN}$ channel isoforms have a finite open probability; moreover, when $V_{\mathrm{m}}$ is stepped back to $-60 \mathrm{mV}$ after a hyperpolarization, closure of HCN channels is rather slow. Therefore, after each hyperpolarization step, a short depolarizing pulse to $-10 \mathrm{mV}$ was performed, which rapidly and completely closed $\mathrm{HCN}$ channels. For all cells, current activation was studied at $V_{\mathrm{m}}=-135 \mathrm{mV}$. HCN1 current amplitude was calculated by subtracting the amplitude of the instantaneous current from the amplitude of the steady-state current at the end of the hyperpolarizing step.

\section{HCN1 knock-out}

HCN1 knock-out animals were obtained from the laboratory of Eric Kandel (Nolan et al., 2003). Knock-out mice were maintained on a 129SvEv background. For experiments, 129SvEv $\mathrm{HCN1}^{-/+}$animals were crossed with $\mathrm{C} 57 \mathrm{Bl} / 6$ wild-type mice, and their hybrid $\mathrm{HCN}^{-/+}$ progeny were intercrossed to produce $\mathrm{HCN1}^{-/-}$and $\mathrm{HCN1}^{+/+}$ littermates. Experimental animals were 6 weeks old and littermates.

\section{Heterologous expression in HEK293 cells}

Whole cell recordings were performed on HEK293 cells that were transiently transfected as previously described (Baumann et al., 1994) with cDNA encoding murine HCN1. Recording conditions were identical to those for retinal slices. 


\section{Ganzfeld electroretinography}

Electroretinograms (ERGs) were obtained according to procedures previously described (Seeliger et al., 2001). In summary, mice were dark-adapted overnight, and their pupils dilated prior to the experiments. The animals were anaesthetized by subcutaneous injection of ketamine $(66.7 \mathrm{mg} / \mathrm{kg})$ and xylazine $(11.7 \mathrm{mg} / \mathrm{kg})$. ERGs were binocularly recorded from the corneal surface by means of gold wire ring electrodes, and silver needle electrodes served as reference (forehead) and ground (tail). The ERG equipment consisted of a Ganzfeld bowl, a DC amplifier, and a PC-based control and recording unit (Toennies Multiliner Vision, Jaeger/Toennies, Höchberg, Germany). Bandpass filter cutoff frequencies were 0.1 and $3000 \mathrm{~Hz}$. Single flash recordings were obtained first under darkadapted (scotopic) and then under light-adapted (photopic) conditions. The light-adapted part was performed with a background illumination of $30 \mathrm{~cd} / \mathrm{m}^{2}$ that started $10 \mathrm{~min}$ before the first recording. Stimuli were presented with increasing intensities from $10^{-4}$ to $25 \mathrm{~cd} \mathrm{~s} / \mathrm{m}^{2}$, divided into 10 steps of 0.5 and $1 \log \mathrm{cd} \mathrm{s} / \mathrm{m}^{2}$. Ten responses were averaged with an interstimulus interval of $5 \mathrm{~s}$ or $17 \mathrm{~s}$ (for 1, 3, 10, $25 \mathrm{~cd} \mathrm{~s} / \mathrm{m}^{2}$ ). Scotopic flicker ERGs were obtained using repetitive stimuli of 0.01 and $0.3 \mathrm{~cd} \mathrm{~s} / \mathrm{m}^{2}$ presented at $1,5,10$ and $30 \mathrm{~Hz}$.

In paired-flash experiments, the test flashes were delivered by the same Ganzfeld equipment as described above, whereas the probe flashes were delivered using a single xenon flash gun (Mecablitz 60CT4; Metz, Zirndorf, Germany) mounted on the Ganzfeld dome. The intensity of this gun was controlled independently, and synchronized with the Ganzfeld flash to allow exact interflash intervals.
A comparable setup has been used extensively in human studies (e.g. Friedburg et al., 2001). Light calibrations were performed using an IL-1700 photometer (International Light, Newburyport, MA, USA) with scotopic (revised Z-CIE) filters.

\section{Results \\ HCN1 is strongly expressed in the mouse retina}

Two independent antibodies raised against different epitopes of $\mathrm{HCN} 1$ (monoclonal antibody RTQ-7C3 against the C-terminus; polyclonal antibody $\mathrm{HCN} 1$ against the $\mathrm{N}$-terminus) were used to study the expression of $\mathrm{HCN} 1$ in the mouse retina by western blot analysis (data not shown) and immunohistochemistry. Both antibodies yielded identical results. HCN1 was expressed throughout the retina (Fig. 1A). In the outer retina, photoreceptors were strongly HCN1immunoreactive. All somata in the outer nuclear layer (ONL) showed immunofluorescence. The strongest HCN1 staining was detected in the photoreceptor inner segments. HCN1 immunoreactivity was also observed along the photoreceptor axons down to the photoreceptor endfeet in the outer plexiform layer (OPL). In the inner nuclear layer, a number of bipolar cells were positive that send dendrites to the OPL and axons to a densely labelled band in the middle of the inner plexiform layer (IPL; Fig. 1A, long arrows). Several other bands in the IPL were also marked. One band in the OFF-sublamina of the IPL (Fig. 1A, arrowhead) seems to originate from amacrine cells rather than bipolar cells, because HCN1-positive processes were not labelled by an antibody against the vesicular glutamate transporter 1 , a marker
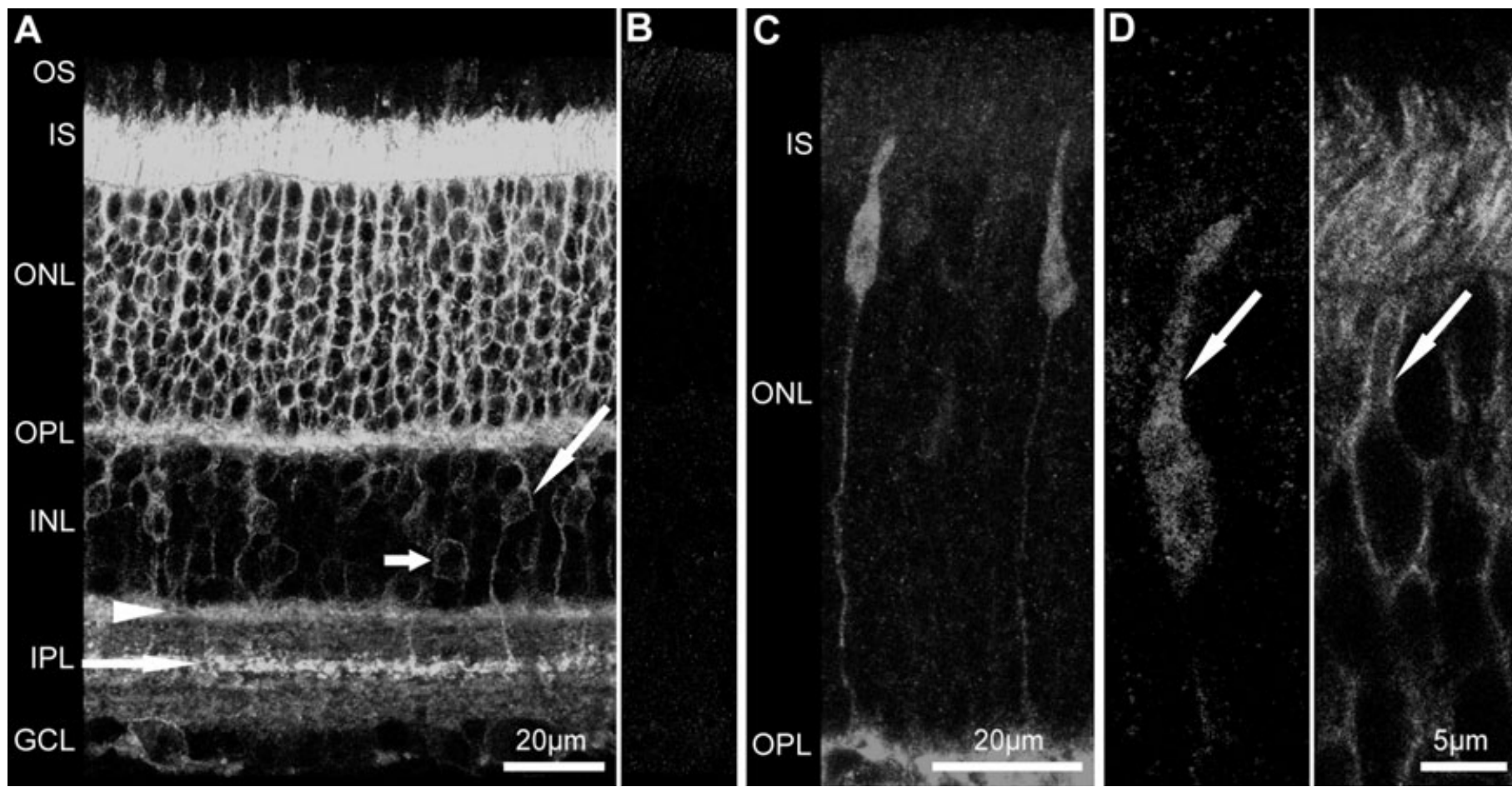

FIG. 1. Immunohistochemical localization of HCN1 in the mouse retina. (A) HCN1-specific antibody labelled photoreceptor inner segments, somata, axons and axon terminals in the outer retina. Somata of bipolar cells (long arrow) and amacrine cells (short arrow) are labelled in the inner nuclear layer (INL), and corresponding bands of bipolar cell axon terminals (long horizontal arrow) and amacrine cell dendrites (arrowhead) are visible in the inner plexiform layer (IPL). Some ganglion cell somata are also HCN1-positive in the ganglion cell layer (GCL). (B) No HCN1 immunoreactivity is observed in retinal sections obtained from HCN1 knock-out animals. (C) CabP5 immunoreactivity is detected in a subset of cone photoreceptors. (D) Double staining against CabP5 (left) and HCN1 (right) shows that HCN1 is present in the plasma membrane of cones (arrow). OS, outer segments; IS, inner segments; ONL, outer nuclear layer; OPL, outer plexiform layer. 
for bipolar cell axon terminals (data not shown). In fact, many amacrine cell bodies at the border of the inner nuclear layer and IPL were immunoreactive for $\mathrm{HCN} 1$ (Fig. 1A, short arrow). In the ganglion cell layer, some somata were labelled. The large diameter of these somata $(15-25 \mu \mathrm{m})$, together with the strongly HCN1immunoreactive axon bundles in the nerve fibre layer, suggest that the majority of these cells are ganglion cells, rather than displaced amacrine cells.

Several lines of evidence suggest that the staining is specific for HCN1. First, in western blots of rat retina (Müller et al., 2003) and mouse retina (data not shown), the antibodies stained a band with the appropriate molecular mass. Second, the same results were obtained using two independent antibodies. If both $\mathrm{HCN} 1$ antibodies were applied to the same section in double labelling experiments, identical structures were stained (data not shown). Third, the staining was absent in retinal sections obtained from HCN1 knock-out mice (Fig. 1B).

In Fig. 1A, a stack of confocal images is collapsed to a single focal plane. Although it is evident that rods are HCN1-immunoreactive, in such a projection it is difficult to decide whether cones, which represent only $3 \%$ of the somata in the ONL (Carter-Dawson \& LaVail, 1979; Jeon et al., 1998), are also stained. Therefore, sections were double-labelled with antibodies against HCN1 and against the calcium-binding protein CabP5 (Haeseleer et al., 2000). In mouse retina, CabP5 was expressed in a subset of photoreceptors in the ONL that can be identified unequivocally as cones (Fig. 1C). Only a subset of cones that also expressed S-opsin were stained for CabP5 (data not shown). In a high-power image of a single confocal section, a cone labelled for CabP5 (Fig. 1D, left panel) is surrounded by a thin rim of HCN1 immunoreactivity, presumably originating from HCN1 channels in the plasma membrane (Fig. 1D, right panel). In most cases, HCN1 immunofluorescence was restricted to the plasma membrane surrounding processes and somata, as expected for the staining of a channel protein.

Both in rat (Müller et al., 2003) and in mouse retina, the strongly HCN1-immunoreactive bipolar cells that terminate close to the middle of the IPL can be identified as type 5 cone bipolar cells. In the mouse retina (Haverkamp et al., 2003), the antiserum against CabP5 labels three bipolar cell types (Fig. 2A, left panel, red): type 3 bipolar cells that stratify in the OFF-sublamina of the IPL (axon terminals are indicated by ' 3 '), type 5 bipolar cells that terminate roughly in the middle of the IPL (' 5 '), and rod bipolar cells that stratify close to the ganglion cell layer ('RB'). Two bipolar cells are indicated by arrowheads. In the bipolar cell on the right, the axon is well stained and can be traced completely. The position of its terminal in the middle of the IPL identifies the cell as type 5 bipolar. The antibody against HCN1 labelled several bipolar cells whose axons can be traced to the middle of the IPL (Fig. 2A, right panel, green). Two of them are the cells indicated in the CabP5 staining (arrowheads). The staining demonstrates that type 5 bipolar cells are HCN1-positive.

In the mouse retina, rod bipolar cells also express HCN1, albeit much more weakly than type 5 bipolar cells. Figure $2 \mathrm{~B}$ shows double labelling for protein kinase $\mathrm{C}$ (left panel, red) to identify rod bipolar cells (Greferath et al., 1990; Haverkamp \& Wässle, 2000) and HCN1 (right panel, green). Several type 5 bipolar cells strongly labelled for HCN1 can be observed to the right. On the left, a group of rod bipolar cells is observed that shows very weak staining for HCN1 (arrowheads). In many instances, HCN1-immunoreactivity was not found at the rod bipolar soma but rather at the axon terminal. Figure $2 \mathrm{C}$ shows a high-power image of rod bipolar axon terminals identified with antibodies against protein kinase $\mathrm{C}$ (red). A thin rim of HCN1 staining (green, arrowheads) can be observed, most probably representing
HCN1 channels in the plasma membrane of the axon terminals. HCN1 is not expressed in all bipolar cell types. For example, type 3 bipolar cells already identified in the CabP5 staining seem to be negative for HCN1. In a high-power view of the IPL (Fig. 2D), axon terminals of type 3 bipolar cells (arrowheads) appear only red (CabP5), whereas type 5 bipolar cells are also stained by antibodies against HCN1 (green), and therefore appear bright yellow (bottom). Somata of type 3 bipolar cells are also negative for HCN1. We recently demonstrated that type 3 bipolar cells can be subdivided into type 3 a bipolar cells, which can be identified by antibodies against HCN4, and type $3 b$ bipolar cells, characterized by strong expression of protein kinase A (Mataruga et al., 2007). In Fig. 2E, type $3 \mathrm{~b}$ cells (blue) and type $3 \mathrm{a}$ cells (red) can be easily distinguished from labelled amacrine cells by their dendrites reaching to the OPL. Type 5 bipolar cells show the typical rim-like HCN1 staining (green); however, no green staining can be observed in type $3 \mathrm{a}$ and $3 \mathrm{~b}$ cells. We studied the expression patterns of all HCN channel isoforms in mouse retina. All isoforms were expressed in wild-type animals (data not shown), but none of them could be detected in rods, rod bipolar cells, or type 5 bipolar cells, indicating that these cell types express only HCN1. Moreover, with the exception of HCN4, which is strongly expressed in type 3a bipolar cells, HCN2-4 isoforms were barely detected above threshold in bipolar cells of the mouse retina.

\section{HCN1 currents are recorded in retinal cells}

The immunohistochemical analysis shown in Figs 1 and 2 predicts HCN1-like currents in rods, rod bipolar cells, and type 5 bipolar cells. As previously shown, HCN1 channels can be distinguished from other HCN channel isoforms by the kinetics of current activation (Moosmang et al., 1999; Müller et al., 2003); for a review, see Kaupp \& Seifert (2001). Whereas channels composed of HCN2, HCN3 or HCN4 display rather slow current activation, with time constants between $200 \mathrm{~ms}$ and several seconds, HCN1 channels activate with time constants $\leq 100 \mathrm{~ms}$. Current activation of mouse HCN1 channels heterologously expressed in HEK293 cells could be fitted by a single exponential $(\tau=60 \pm 11 \mathrm{~ms} ; n=8)$. Hyperpolarization-activated currents that develop with similar time constants were recorded in rods, rod bipolar cells and type 5 bipolar cells in retinal slices obtained from wild-type mice. Upon hyperpolarization, all three cell types displayed inward currents that were composed of two components: an instantaneous current (Fig. 3A, arrowhead) and a slowly activating current (Fig. 3A, arrow). The instantaneous currents were most likely carried by inwardly rectifying $\mathrm{K}^{+}$channels, because current amplitudes were considerably reduced in the presence of $0.3 \mathrm{mM} \mathrm{Ba}^{2+}$ (data not shown). Inwardly rectifying $\mathrm{K}^{+}$channels were described in a variety of bipolar cells in the rat retina (Ma et al., 2003; Ivanova \& Müller, 2006) and in Xenopus rods (Akopian \& Witkovsky, 1996). Several lines of evidence indicate that the slowly activating currents were carried by HCN1. First, currents activated with time constants that are typical for HCN1 but too fast for HCN2-4. In rods, HCN1 currents displayed an amplitude of $-27 \pm 9 \mathrm{pA}$, and $\tau$ was $31 \pm 8 \mathrm{~ms}$ $(n=7)$. In rod bipolar cells, current amplitudes were smaller $(-14 \pm$ $3 \mathrm{pA})$, and current activation was slightly slower $(\tau=63 \pm 24 \mathrm{~ms}$, $n=6)$. HCN1 currents were largest in type 5 bipolar cells $(-39 \pm$ $7 \mathrm{pA}, \tau=112 \pm 33 \mathrm{~ms}, n=3)$. In all three cell types, HCN1 currents were reversibly blocked by $3 \mathrm{~mm}$ extracellular $\mathrm{Cs}^{+}$(Fig. 3A inset; please note that $\mathrm{Cs}^{+}$also reduced the instantaneous current component, as has been described for inwardly rectifying $\mathrm{K}^{+}$currents) (Hagiwara et al., 1976). Finally, in rods, rod bipolar cells and type 5 bipolar cells recorded in retinal slices obtained from HCN1 knock-out 

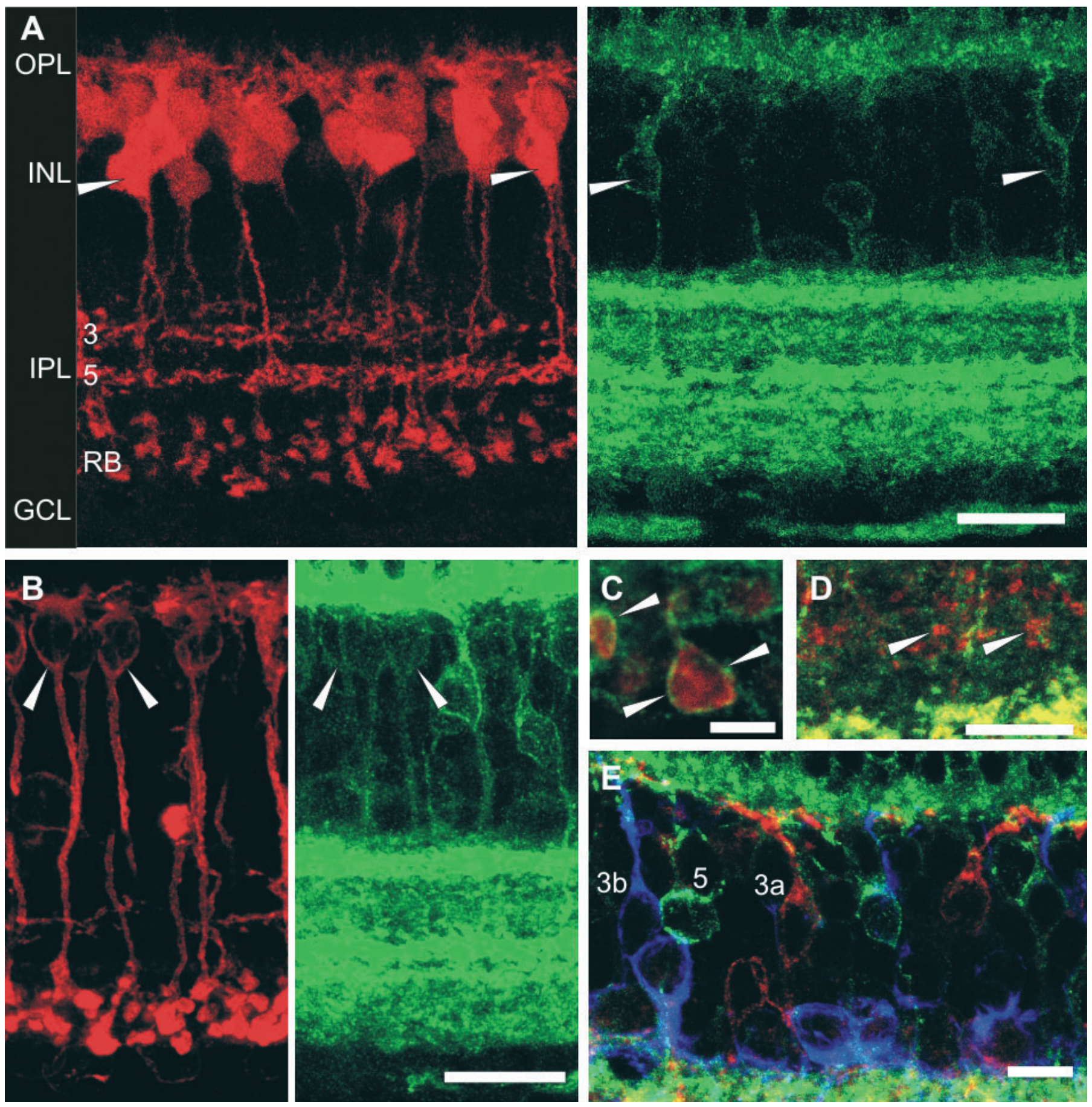

FIG. 2. HCN1 in bipolar cells. (A) Double labelling for CabP5 (left, red) and HCN1 (right, green). CabP5 is detected in three types of bipolar cells and their axon terminals in the inner plexiform layer (IPL): 3 , type 3 bipolar cells; 5 , type 5 bipolar cells; RB, rod bipolar cells (left). Two type 5 bipolar cells are marked (arrowheads), whose axon terminal systems can be traced completely. Both cells are also positive for HCN1 (right). (B) Double labelling for protein kinase C (PKC) (left, red) and HCN1 (right, green). PKC staining identifies somata and axons of rod bipolar cells. Arrowheads indicate two cells that are also weakly labelled for HCN1 (right). (C) High-power view of rod bipolar cell axon terminals (PKC, red). HCN1 immunoreactivity (green) is found in a thin rim around the terminal. (D) High-power view of the IPL. Axon terminals (arrowheads) of type 3 bipolar cells (red, CabP5) are negative for HCN1 (green). (E) Type 3a (red, HCN4) and 3b (blue, PKARII $\beta$ ) are negative for HCN1 (green). Scale bars: $10 \mu \mathrm{m}$, except in C $(2 \mu \mathrm{m})$. OPL, outer plexiform layer; INL, inner nuclear layer; GCL, ganglion cell layer.

animals (littermates of wild-type animals, Fig. 3B), the slowly activating currents were absent, whereas instantaneous currents during hyperpolarization and outward currents during depolarization were similar to those found in cells of wild-type littermates. In summary, the data show that HCN1 currents can be recorded from wild-type cells, but are absent in cells of knock-out mice. Most importantly, recordings clearly demonstrate that the loss of $\mathrm{HCN} 1$ channels was not compensated for by expression of other HCN channel subtypes in rods, rod bipolar cells, and type 5 bipolar cells. Apart from the total loss of HCN1 channels, the electrophysiological properties of the 
A

\section{wt}

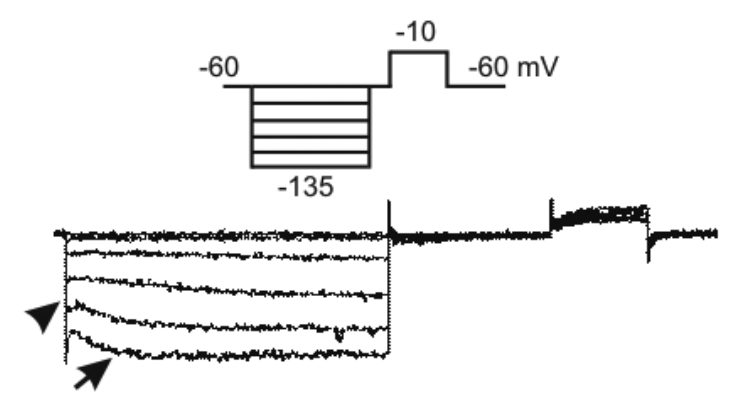

rod

rod

bipolar
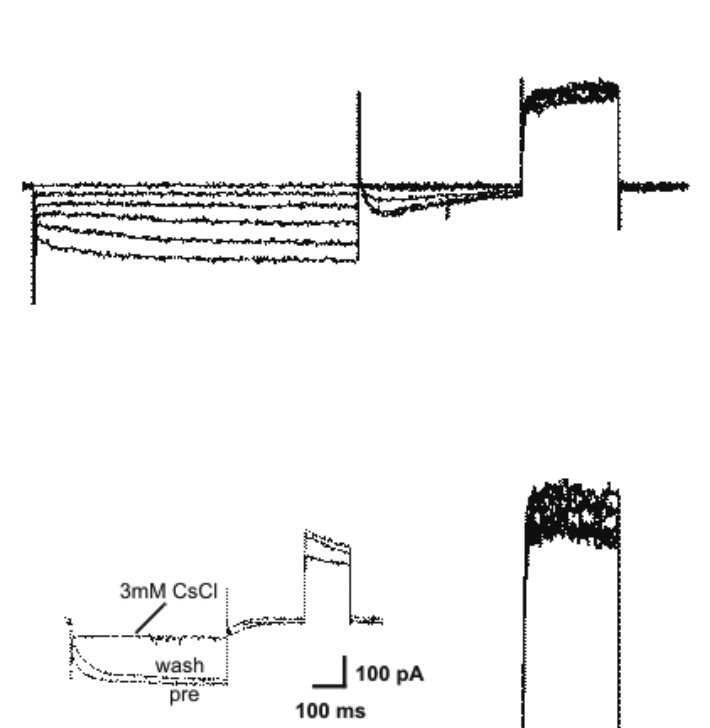

\section{type 5 bipolar}
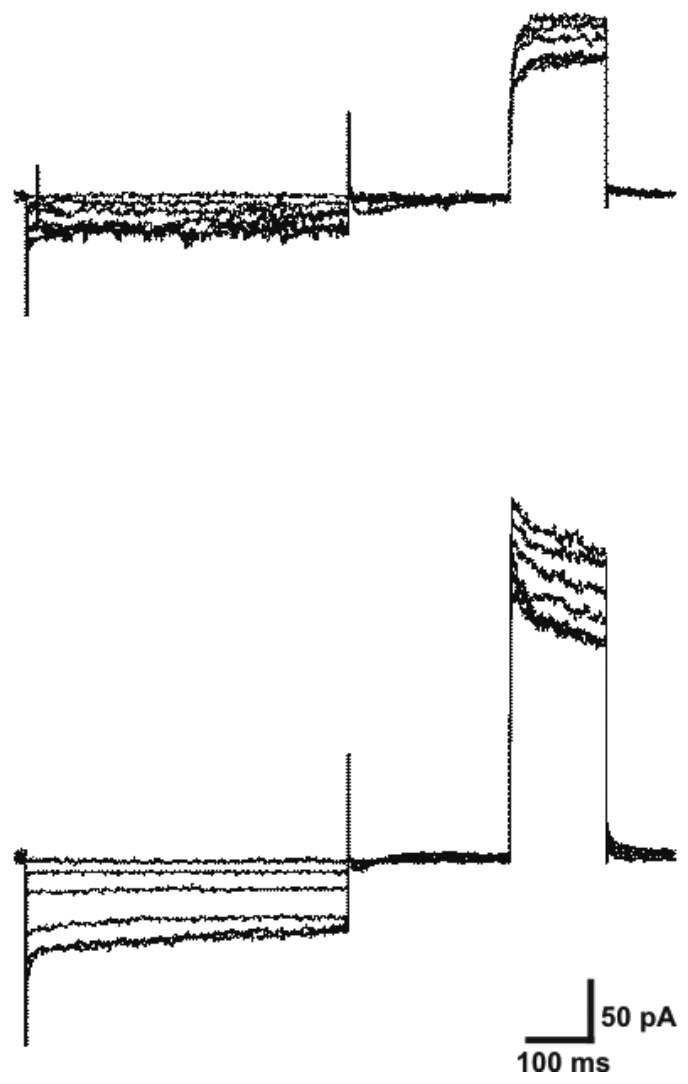

FIG. 3. HCN1 currents are found in rods, rod bipolar cells, and type 5 bipolar cells. (A) Upper panel, voltage-clamp protocol: membrane potential $\left(V_{\mathrm{m}}\right)$ was stepped from -60 to $-135 \mathrm{mV}$ in $-15 \mathrm{mV}$ increments for $500 \mathrm{~ms}$. Lower panels: inward currents in cells of wild-type animals (wt) have an instantaneous component (arrowhead) and a slowly developing component (arrow) that originates from HCN1 channels. Inset: HCN1 currents could be reversibly blocked by 3 mM Cs ${ }^{+}$(at $V_{\mathrm{m}}=-135 \mathrm{mV}$ ). (B) In cells from $\mathrm{HCN} 1$ knock-out animals $\left(\mathrm{HCN1}^{-/-}\right)$, $\mathrm{HCN} 1$ currents are missing, whereas instantaneous inward currents and outward currents upon depolarization are similar to those of wild-type animals.

retinal cells were, by and large, unchanged and the retina of the HCN1 knock-out mice showed no pathological changes (data not shown). Therefore, the HCN1 knock-out mouse is a good model with which to study the role of HCN1 in retinal information processing. In the following, we studied scotopic and photopic light responses in the ERG of wild-type mice and HCN1 knock-out mice.

\section{Light responses are prolonged in HCN1 knock-out mice}

The murine Ganzfeld ERG is a measure of overall retinal function. We performed single-flash ERG recordings under scotopic and photopic adaptation conditions and with different stimulus intensities (Fig. 4). Wild-type and HCN1 knock-out animals were littermates (6 weeks of age). Representative records of a wild-type mouse are shown in the left columns of Fig. 4A (scotopic) and Fig. 4B (photopic). Typically, ERG waveforms consist of an early negativegoing component that is best visible at high light intensities, the a-wave, followed by a large positive-going component, the b-wave. Whereas at least the initial portion of the a-wave reflects the primary light response in photoreceptors, the b-wave is dominated by the activity of ON-bipolar cells. Riding on top of the b-wave are the oscillatory potentials, small wavelets that probably involve inner 
A

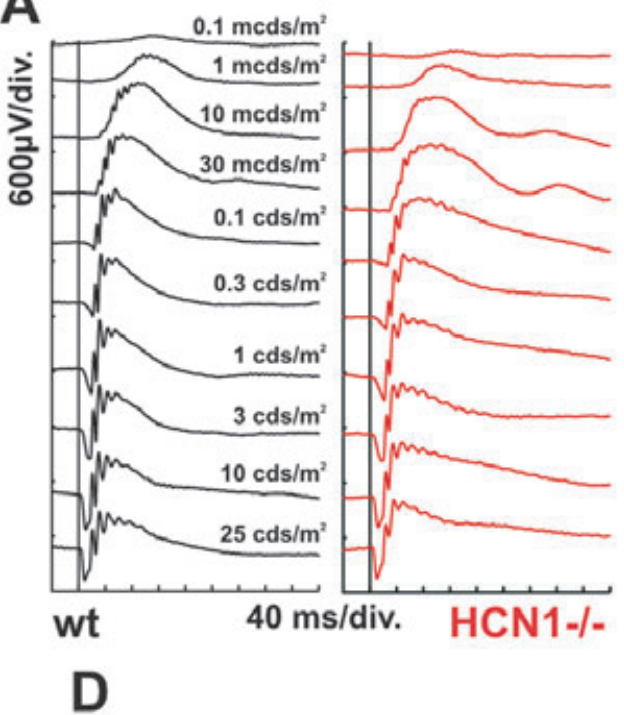

B

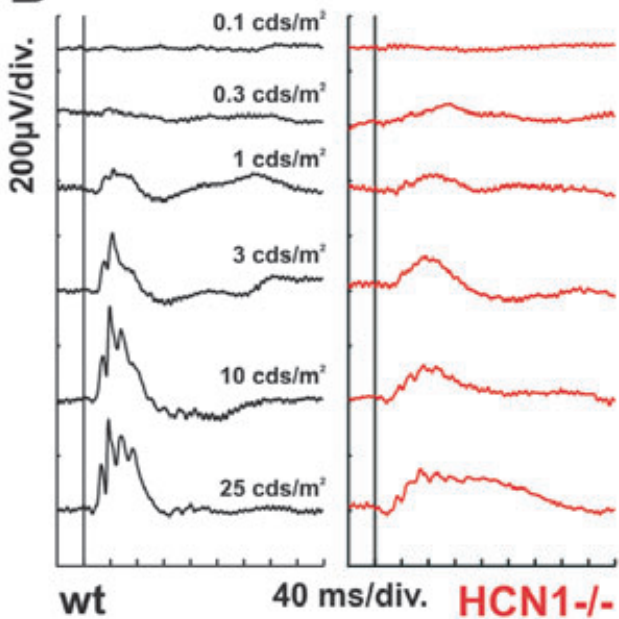

C
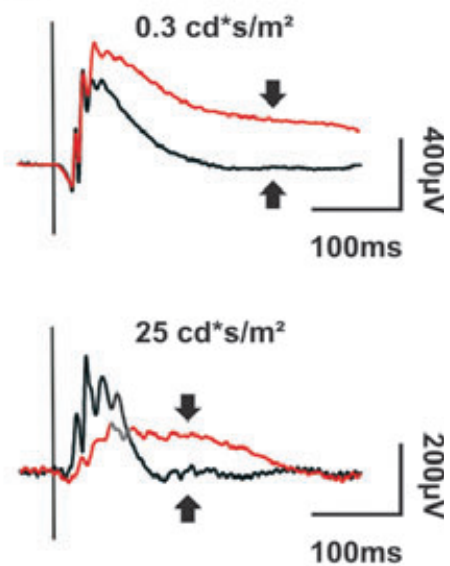

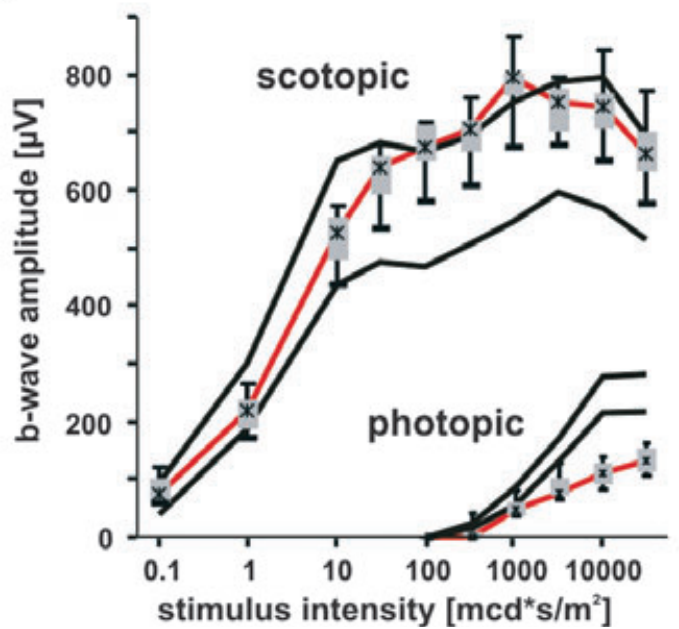

E

. Effect of HCN1 deficiency on retinal function under scotopic and photopic conditions. Direct comparison of flash ERG recordings in dark-adapted (A) and light-adapted (B) wild-type (wt) and knock-out $\left(\mathrm{HCN1}^{-/-}\right)$mice. (C) Superposition of recordings from wild-type and knock-out animals reveals that light responses are considerably prolonged in knock-out mice. The prolongation is associated with only a minor rise in scotopic b-wave amplitude, whereas there is a decrease in the photopic b-wave amplitude. (D) Statistical evaluation of the corresponding ERG b-wave data. Boxes indicate the $25 \%$ and $75 \%$ quantile range, whiskers the $5 \%$ and $95 \%$ quantiles, and the asterisks the median of the $\mathrm{HCN1}^{-/-}$data. The normal range is delimited by black lines indicating the $5 \%$ and $95 \%$ quantiles of the wild-type data. (E) Amplitude of scotopic ERG traces $200 \mathrm{~ms}$ after the flash stimulus, relative to the baseline before stimulation. The thick lines represent the median and the filled areas, delimited by thin lines, indicate the $5 \%$ and $95 \%$ quantiles, the $90 \%$ probability range of the knock-out and wild-type data. At the chosen time point, the difference between $\mathrm{HCN1}^{-/-}$and wild-type mice became apparent at about $1 \mathrm{mcd} \mathrm{s} / \mathrm{m}^{2}$, grew in size up to about $0.1 \mathrm{~cd} \mathrm{~s} / \mathrm{m}^{2}$, and stayed at approximately $300 \mu \mathrm{V}$ at higher intensities.

retinal circuitry [for a review on the origin of ERG components, see Pugh et al. (1998)].

In the scotopic regime, the knock-out of HCN1 channels had no substantial effect on the onset of the ERG response or the amplitudes of the a- and b-waves (Fig. 4A and D). In the statistical analysis (Fig. 4D, $n=4$ for both wild-type and HCN1 knock-out animals), the scotopic b-wave amplitude data recorded from HCN1 knock-out animals (box plots) fall well within the black lines that limit the 5-95\% normal range of the wild-type data. In contrast, the photopic (light-adapted) responses were reduced and their oscillatory components were also diminished (Fig. 4B and D). The most prominent effect of HCN1 knock-out concerned the duration of light responses. Under both scotopic and photopic conditions, the b-wave was considerably prolonged in HCN1 knock-out animals at higher light intensities (scotopic, Fig. 4A and C, upper panel; photopic, Fig. 4B and $\mathrm{C}$, lower panel). This prolongation led to a delayed return of the light-evoked responses to baseline, which is quantified in Fig. 4E for the scotopic ERG. At the chosen time point of $200 \mathrm{~ms}$ after stimulation, an amplitude difference between HCN1 knock-out and wild-type mice became manifest above about $1 \mathrm{mcd} \mathrm{s} / \mathrm{m}^{2}$, then increased up to about $0.1 \mathrm{~cd} \mathrm{~s} / \mathrm{m}^{2}$, and averaged approximately $300 \mu \mathrm{V}$, which is roughly one-half of the maximal b-wave, at higher intensities.

As single flash responses are prolonged, it is tempting to speculate that the flicker fusion frequency, i.e. the ability to respond to repetitive stimulation, should be reduced. Figure 5 compares ERG recordings in wild-type and HCN1 knock-out animals subjected to repetitive light stimuli at different frequencies and different light intensities. At low flash intensities $\left(10 \mathrm{mcd} \mathrm{s} / \mathrm{m}^{2}\right)$, light responses in wild-type and knock-out animals were similar, presumably because the hyperpolarization of the photoreceptors was too small to activate HCN1 channels (Fig. 5A; compare also Fig. 4A and E). In contrast, at higher flash 


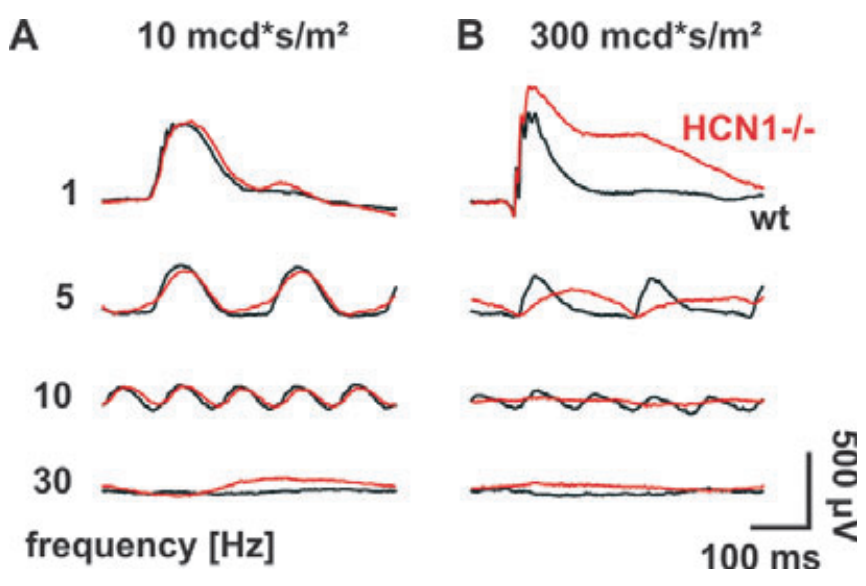

FIG. 5. Effect of HCN1 deficiency on scotopic ERG flicker fusion frequency. (A) At low flash intensities such as $0.01 \mathrm{~cd} \mathrm{~s} / \mathrm{m}^{2}$, no substantial differences between wild-type (wt) and knock-out mice were observed. (B) At higher flash intensities such as $0.3 \mathrm{~cd} \mathrm{~s} / \mathrm{m}^{2}$, the apparent prolongation of the waveform led to a marked reduction in the ability to follow high-frequency stimulation.

intensities, such as $300 \mathrm{mcd} \mathrm{s} / \mathrm{m}^{2}$, which caused a manifest prolongation of the responses (Fig. 4E), there was a remarkable reduction of the ability to follow higher-frequency flicker in the knock-out animals (Fig. 5B).

HCN1 channels are found in the inner segment of photoreceptors, but not in the outer segment (Fig. 1). Therefore, the loss of HCN1 channels should not affect photoreceptor outer segment currents. As the time course of such photoreceptor activity is not directly accessible under most conditions, an indirect method, the paired-flash technique, has been designed (Friedburg et al., 2001). It is based on the fact that a flash of light activates phototransduction, which leads to an electrical response by temporary closure of cGMP-gated channels. The response to a strong stimulus (called a 'probe') that virtually closes all channels can be reduced by a previous weak stimulus (called a 'test'), as the number of channels available for closure is lower. The time course of the photoreceptor response can thus be estimated one point at a time by test-probe sequences with varying delay times. Here, it was found that the lack of HCN1 channels did not alter the time course of photoreceptor recovery even at test flash intensities causing a substantial b-wave prolongation and a maximal amplitude difference at $200 \mathrm{~ms}$ after stimulation in the single flash ERG (Fig. 6).

\section{Discussion}

\section{HCN1 channels in the mouse retina}

HCN1 channels are widely expressed in the retina. Our immunohistochemical analysis revealed particularly strong expression of HCN1 in photoreceptors. In the inner retina, we detected HCN1 in two populations of bipolar cells, the cone ON-bipolar cell type 5 and the rod bipolar cell. HCN1 is also expressed in subpopulations of amacrine cells and ganglion cells that were not further analysed in the present study.

HCN currents were first detected in rod photoreceptors of the retina (Fain et al., 1978), where they curtail the hyperpolarizing light response at high light intensities by allowing an inward current that depolarizes the cell. HCN1 channels are well suited to quickly resist hyperpolarization, because they activate faster than other $\mathrm{HCN}$ channel isoforms (Moosmang et al., 1999; Müller et al., 2003). In agreement with this idea, HCN channels with very fast activation kinetics have been reported in all vertebrate photoreceptors investi-

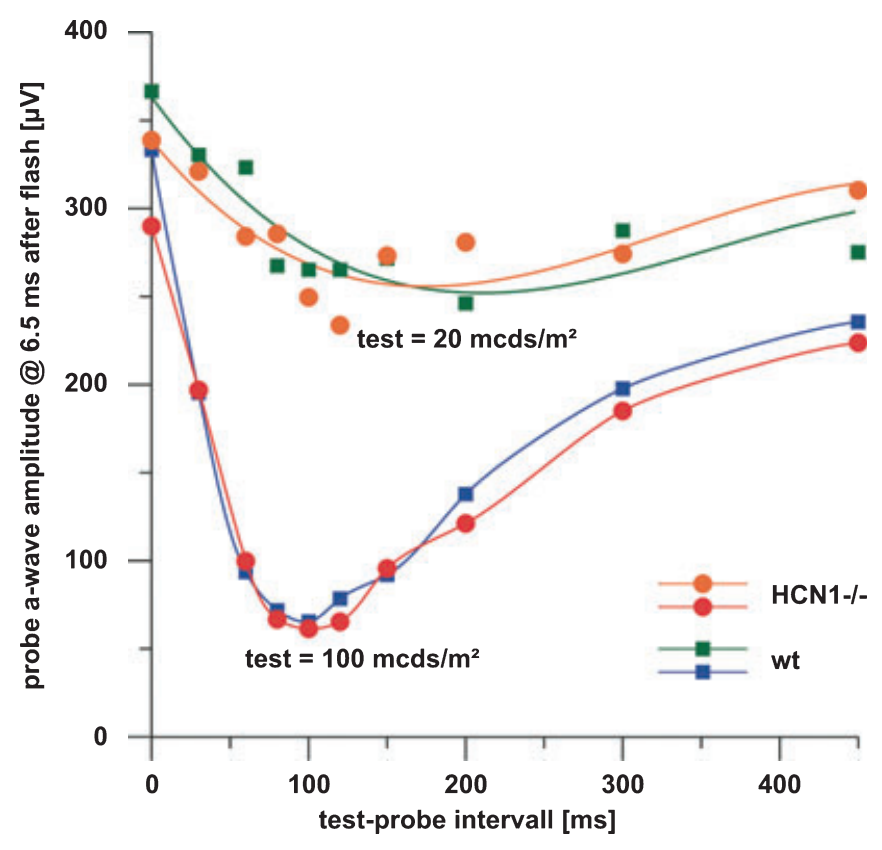

FIG. 6. Effect of HCN1 deficiency on rod outer segment function under scotopic conditions assessed with the paired-flash method. The time course of the reduction of the circulating current, indicated by the degree of a-wave reduction at $6.5 \mathrm{~ms}$ following the probe flash, is shown for a low and a high test flash intensity ( 0.02 and $0.1 \mathrm{~cd} \mathrm{~s} / \mathrm{m}^{2}$, respectively). No differences in outer segment currents between wild-type and HCN1-deficient animals were found, indicating that the action of HCN1 in the inner segment is independent of phototransduction in the outer segment.

gated so far (e.g. Barnes \& Hille, 1989; Demontis et al., 2002). In this study, we show that HCN1 channels in rod photoreceptors activate faster than HCN1 channels in other cell types. This suggests that HCN1 channels are modulated in different ways in different retinal cell types. A possible mechanism for modulation could be the binding of cAMP; however, HCN1 channels are the least susceptible of the $\mathrm{HCN}$ family to such modulation (Santoro et al., 1998) [compare with HCN2 (Ludwig et al., 1998)]. Alternatively, HCN channels may be modulated by phosphorylation (Yu et al., 1995, 2004; Cathala \& Paupardin-Tritsch, 1997). Finally, properties of HCN channels are modulated by the interaction of the channels with components of the plasma membrane, such as phosphatidyl-inositol-bis-phosphate (Pian et al., 2006; Zolles et al., 2006), or lipid metabolites, such as arachidonic acid (Fogle et al., 2007). Future experiments will have to unravel the molecular mechanisms of HCN channel modulation in the retina and the impact of these modulations on information processing in the retinal network.

The data shown in Fig. 3 were obtained from retinal slices of wild-type and HCN1 knock-out animals that were littermates, and therefore had a similar genetic background. Although not within the focus of the present study, we also recorded HCN1 currents in slices obtained from mice with other genetic backgrounds: C57Bl/6, which serves as a 'standard strain' in physiological experiments; and 129SV, the strain in which the HCN-1 knock-out was established (data not shown). In all three backgrounds, we recorded hyperpolarization-activated currents with properties typical for HCN1, yet HCN1 currents in bipolar cells seem to have larger amplitudes and faster activation kinetics in $\mathrm{C} 57 \mathrm{Bl} / 6$ animals. Although a detailed statistical analysis would require a larger set of data, which was beyond the scope of the present study, these preliminary data suggest that HCN1 channel modulation may also depend on the genetic 
background of the animals. However, such differences are of no importance for the current study, as we recorded ERGs in littermates of the same genetic background.

\section{Light responses are altered in HCN1 knock-out mice}

ERG recordings in the scotopic regime show that deletion of HCN1 has no effect on the sensitivity of the light responses. The amplitudes of both a-waves and b-waves are similar to those of normal mice, and develop in the same range of light intensities, in agreement with the fact that HCN1 channels are not involved in the onset of the light response. In contrast, HCN1 channels are involved in the termination of the light response. At higher light intensities, the b-wave component of the ERG is clearly prolonged in HCN1 knock-out animals. This holds true for both scotopic and photopic responses.

The b-wave of the ERG reflects primarily the activity of ON-bipolar cells. In wild-type animals, HCN1 is expressed in rod and cone photoreceptors, as well as in rod bipolar cells, which contribute significantly to the b-wave amplitude in the scotopic range, and in type 5 cone ON-bipolar cells, which are involved in the generation of the photopic b-wave. In the following, we will argue that the prolonged b-wave is mostly due to the loss of HCN1 in photoreceptors, rather than in bipolar cells. ON-bipolar cells give depolarizing light responses during which HCN channels are closed. The loss of HCN1 in these bipolar cells could only prolong the b-wave if one assumes the following scenario in wild-type cells. During darkness, ON-bipolar cells are strongly hyperpolarized and some HCN channels are open. These channels would conduct a depolarizing current. During the light response, the ON-bipolar cell depolarizes. However, because HCN channel closure upon depolarization is rather slow, open HCN channels could still contribute to depolarization of the bipolar cell at light onset, but not during the sustained response, when all HCN channels have become closed. In this way, HCN1 channels in bipolar cells might lead to more transient responses. However, it is more likely that the prolonged b-wave is due to the loss of $\mathrm{HCN} 1$ in photoreceptors.

In photoreceptors, HCN1 channels serve to curtail the hyperpolarizing light response. If $\mathrm{HCN} 1$ channels are pharmacologically blocked (Fain et al., 1978; Satoh \& Yamada, 2000), both the amplitude and the duration of the hyperpolarizing light response are increased. The impact of HCN channels is expected to be particularly pronounced at higher light intensities that strongly hyperpolarize photoreceptors, and, as a consequence, activate HCN channels more effectively. As photoreceptors relay the (prolonged) light response via a decrease of glutamate release to ON-bipolar cells, in HCN1 knock-out animals prolonged bipolar cell responses are expected upon stimulation with bright light. This is indeed observed in our recordings. At high but not at low light intensities, the b-wave is prolonged in the HCN1 knockout mice in both scotopic and photopic ERGs.

The photopic b-wave and its oscillatory components are diminished in the HCN1 knock-out mice. Oscillatory components commonly correlate with the photopic b-wave amplitude; thus, the reduction in b-wave amplitude may explain the reduction in oscillatory components observed [for review, see Wachtmeister (1998)]. The reason for the reduced photopic b-wave is unknown and has to be elucidated in further studies.

In previous studies, the role of HCN channels was investigated in isolated photoreceptors and in ERG recordings. Demontis et al. (2002) showed that the electrotonic properties of individual photoreceptors changed upon application of HCN channel blockers, and concluded that $\mathrm{HCN}$ channels contribute to the bandpass properties of photoreceptors. Gargini and coworkers investigated the function of $\mathrm{HCN}$ channels in the intact retina using a pharmacological approach. In ERG recordings performed upon injection of HCN channel blockers into the vitreous of anaesthetized cats or upon systemic application in humans, the authors found a pronounced reduction in the response to high flicker frequencies (Gargini et al., 1999a, b). However, the interpretation of pharmacological blockage data is difficult, as this approach has some potential limitations. In a recent study, we found that all four HCN channel isoforms are differentially expressed in rat retina (Müller et al., 2003). This also holds true for the mouse retina, although there are certain differences between species that will be described in detail elsewhere (A. Mataruga and F. Müller, unpublished results). HCN channel blockers do not discriminate well between HCN channel isoforms. Therefore, upon injection of blockers into the vitreous, all $\mathrm{HCN}$ channels throughout the retina will be blocked, and it is difficult to relate the effects to a given $\mathrm{HCN}$ isoform in a given cell type. Moreover, $\mathrm{HCN}$ channel blockers that are currently used are not very specific for HCN channels. The best known agent, ZD7288, also affects calcium conductances (Felix et al., 2003) and might influence synaptic transmission (Chen \& Chen, 2004). Finally, when applied on the systemic level, HCN channel blockers will strongly reduce the heart rate, and could therefore compromise retinal function.

To study the function of $\mathrm{HCN} 1$ channels in the retina, we favoured a genetic rather than a pharmacological approach, in which exclusively HCN1 channels are deleted. Our patch-clamp analysis at the level of single identified neurons showed that the loss of HCN1 is not compensated for by upregulation of other HCN channel isoforms. Moreover, HCN2-4 are not expressed in mouse photoreceptors (A. Mataruga and F. Müller, unpublished observations) and are only barely detected above threshold in ON-bipolar cells. Hence, no other $\mathrm{HCN}$ channel isoform could compensate for the loss of HCN1 in the ERG recordings shown here. Therefore, the retina of HCN1 knock-out animals provides a valuable system with which to study the role of $\mathrm{HCN} 1$ in the shaping and processing of retinal light responses. Preliminary experiments performed with the patch-clamp technique in the isolated retina of $\mathrm{HCN} 1$ knock-out mice indicate that the light responses of individual ganglion cells are also changed (G. Knop and F. Müller, unpublished data). Future studies will have to focus on the impact of $\mathrm{HCN} 1$ in the response of the retina to repetitive stimulation and in the generation of complex light responses at the level of individual identified cells.

\section{Acknowledgements}

We thank Dr Eric Kandel (Columbia University, USA) for providing the HCN knock-out line, Christoph Aretzweiler for technical assistance in immunohistochemistry and genotyping of HCN1 knock-out animals, Mechthilde Bruns for help in cell culture, and Dr Wolfgang Bönigk for the cDNA of murine HCN1. M. W. Seeliger was supported by the Deutsche Forschungsgemeinschaft (DFG Se837/4-1 and Se837/5-1).

\section{Abbreviations}

ERG, electroretinogram; GCL, ganglion cell layer; HCN, hyperpolarizationactivated and cyclic nucleotide-gated; INL, inner nuclear layer; IPL, inner plexiform layer; IS, inner segments; ONL, outer nuclear layer; OPL, outer plexiform layer; OS, outer segments; PB, phosphate buffer; $V_{\mathrm{m}}$, membrane potential.

\section{References}

Akopian, A. \& Witkovsky, P. (1996) D2 dopamine receptor-mediated inhibition of a hyperpolarization activated current in rod photoreceptors. J. Neurophysiol., 76, 1828-1835. 
Barnes, S. \& Hille, B. (1989) Ionic channels of the inner segment of tiger salamander cone photoreceptors. J. Gen. Physiol., 94, 719-743.

Baumann, A., Frings, S., Godde, M., Seifert, R. \& Kaupp, U.B. (1994) Primary structure and functional expression of a Drosophila cyclic nucleotide-gated channel present in eyes and antennae. EMBO J., 13, 5040-5050.

Baylor, D.A., Matthews, G. \& Nunn, B.J. (1984) Location and function of voltage-sensitive conductances in retinal rods of the salamander, Ambystoma tigrinum. J. Physiol., 354, 203-223.

Carter-Dawson, L.D. \& LaVail, M.M. (1979) Rods and cones in the mouse retina. J. Comp. Neurol., 188, 245-262.

Cathala, L. \& Paupardin-Tritsch, D. (1997) Neurotensin inhibition of the hyperpolarization-activated cation current $\left(I_{\mathrm{h}}\right)$ in the rat substantia nigra pars compacta implicates the protein kinase C pathway. J. Physiol., 503, 87-97.

Chen, C. \& Chen, C. (2004) ZD7288 inhibits postsynaptic glutamate receptormediated responses at hippocampal perforant path-granule cell synapses. Eur. J. Neurosci., 19, 643-649.

Demontis, G.C., Moroni, A., Gravante, B., Altomare, C., Longoni, B., Cervetto, L. \& DiFrancesco, D. (2002) Functional characterisation and subcellular localisation of HCN1 channels in rabbit retinal rod photoreceptors. J. Physiol., 542, 89-97.

Euler, T. \& Wässle, H. (1995) Immunocytochemical identification of cone bipolar cells in the rat retina. J. Comp. Neurol., 361, 461-478.

Fain, G.L., Quandt, F.N., Bastian, B.L. \& Gerschenfeld, H.M. (1978) Contribution of a caesium-sensitive conductance increase to the rod photoresponse. Nature, 272, 467-469.

Felix, R., Sandoval, A., Sánchez, D., Gómora, J.C., de la Vega-Beltrán, J.L., Treviño, C.L. \& Darszon, A. (2003) ZD7288 inhibits low-threshold $\mathrm{Ca}^{2+}$ channel activity and regulates sperm function. Biochem. Biophys. Res. Commun., 311, 187-192.

Fogle, K.J., Lyashchenko, A.K., Turbendian, H.K. \& Tibbs, G.R. (2007) HCN pacemaker channel activation is controlled by acidic lipids downstream of diacylglycerol kinase and phospholipase. J. Neurosci., 27, 2802-2814.

Friedburg, C., Thomas, M.M. \& Lamb, T.D. (2001) Time course of the flash response of dark- and light-adapted human rod photoreceptors derived from the electroretinogram. J. Physiol., 534, 217-242.

Gargini, C., Demontis, G.C., Bisti, S. \& Cervetto, L. (1999a) Effects of blocking the hyperpolarization-activated current $\left(I_{\mathrm{h}}\right)$ on the cat electroretinogram. Vision Res., 39, 1767-1774.

Gargini, C., Demontis, G.C., Bisti, S. \& Cervetto, L. (1999b) Temporal fidelity in the visual system. Arch. Ital. Biol., 137, 299-309.

Ghosh, K.K., Bujan, S., Haverkamp, S., Feigenspan, A. \& Wässle, H. (2004) Types of bipolar cells in the mouse retina. J. Comp. Neurol., 469, 70-82.

Greferath, U., Grünert, U. \& Wässle, H. (1990) Rod bipolar cells in the mammalian retina show protein kinase C-like immunoreactivity. J. Comp. Neurol., 301, 433-442.

Haeseleer, F., Sokal, I., Verlinde, C.L., Erdjument-Bromage, H., Tempst, P., Pronin, A.N., Benovic, J.L., Fariss, R.N. \& Palczewski, K. (2000) Five members of a novel $\mathrm{Ca}^{2+}$-binding protein (CABP) subfamily with similarity to calmodulin. J. Biol. Chem., 275, 1247-1260.

Hagiwara, S., Miyazaki, S. \& Rosenthal, N.P. (1976) Potassium current and the effect of cesium on this current during anomalous rectification of the egg cell membrane of a starfish. J. Gen. Physiol., 67, 621-638.

Hartveit, E. (1997) Functional organization of cone bipolar cells in the rat retina. J. Neurophysiol., 77, 1716-1730.

Haverkamp, S. \& Wässle, H. (2000) Immunocytochemical analysis of the mouse retina. J. Comp. Neurol., 424, 1-23.

Haverkamp, S., Gosh, K.K., Hirano, A.A. \& Wässle, H. (2003) Immunocytochemical description of five bipolar cell types of the mouse retina. J. Comp. Neurol., 455, 463-476.

Hestrin, S. (1987) The properties and function of inward rectification in rod photoreceptors of the tiger salamander. J. Physiol., 390, 319-333.

Ivanova, E. \& Müller, F. (2006) Retinal bipolar cell types differ in their inventory of ion channels. Vis. Neurosci., 23, 143-154.

Jeon, C.-J., Strettoi, E. \& Masland, R.H. (1998) The major cell populations of the mouse retina. J. Neurosci., 18, 8936-8946.

Kaupp, U.B. \& Seifert, R. (2001) Molecular diversity of pacemaker ion channels. Annu. Rev. Physiol., 63, 235-257.

Ludwig, A., Zong, X., Jeglitsch, M., Hofmann, F. \& Biel, M. (1998) A family of hyperpolarization-activated mammalian cation channels. Nature, 393, 587-591.
Ludwig, A., Zong, X., Stieber, J., Hullin, R., Hofmann, F. \& Biel, M. (1999) Two pacemaker channels from human heart with profoundly different activation kinetics. EMBO J., 18, 2323-2329.

Ma, Y.P., Cu, J., Hu, H.J. \& Pan, Z.H. (2003) Mammalian retinal bipolar cells express inwardly rectifying $\mathrm{K}^{+}$currents (IKir) with a different distribution than that of $\mathrm{I}_{\mathrm{h}}$. J. Neurophysiol., 90, 3479-3489.

Magee, J.C. (1998) Dendritic hyperpolarization-activated currents modify the integrative properties of hippocampal CA1 pyramidal neurons. $J$. Neurosci., 18, 7613-7624.

Masland, R.H. (2001) The fundamental plan of the retina. Nat. Neurosci., 4, 877-886.

Mataruga, A., Kremmer, E. \& Müller, F. (2007) Type 3a and type 3b OFF cone bipolar cells provide for the alternative rod pathway in the mouse retina. J. Comp. Neurol., 502, 1123-1137.

Moosmang, S., Biel, M., Hofmann, F. \& Ludwig, A. (1999) Differential distribution of four hyperpolarization-activated cation channels in mouse brain. Biol. Chem, 380, 975-980.

Müller, F., Scholten, A., Ivanova, E., Haverkamp, S., Kremmer, E. \& Kaupp, U.B. (2003) HCN channels are expressed differentially in retinal bipolar cells and concentrated at synaptic terminals. Eur. J. Neurosci., 17, 2084 2096

Nolan, M.F., Malleret, G., Lee, K.H., Gibbs, E., Dudman, J.T., Santoro, B., Yin, D., Thompson, R.F., Siegelbaum, S.A., Kandel, E.R. \& Morozov, A. (2003) The hyperpolarization-activated HCN1 channel is important for motor learning and neuronal integration by cerebellar Purkinje cells. Cell, 115, 551-564.

Pape, H.-C. (1996) Queer current and pacemaker: the hyperpolarization-activated cation current in neurons. Annu. Rev. Physiol., 58, 299-327.

Pian, P., Bucchi, A., Robinson, R.B. \& Siegelbaum, S.A. (2006) Regulation of gating and rundown of HCN hyperpolarization-activated channels by exogenous and endogenous $\mathrm{PIP}_{2}$. J. Gen. Physiol., 128, $593-$ 604.

Pignatelli, V. \& Strettoi, E. (2004) Bipolar cells in the mouse retina: a gene gun, morphological study. J. Comp. Neurol., 476, 254-266.

Pugh, E.N. Jr, Falsini, B. \& Lyubarsky, A.L. (1998) The origin of the major rod- and cone-driven components of the rodent electroretinogram, and the effect of age and light-rearing history on the magnitude of these components. In Williams, T.P. \& Thistle, A.B. (Eds), Photostasis and Related Topics. Plenum Press, New York, pp. 93-128.

Robinson, R.B. \& Siegelbaum, S.A. (2003) Hyperpolarization-activated cation currents: from molecules to physiological function. Annu. Rev. Physiol., 65, 453-480.

Santoro, B., Liu, D.T., Yao, H., Bartsch, D., Kandel, E.R., Siegelbaum, S.A. \& Tibbs, G.R. (1998) Identification of a gene encoding a hyperpolarizationactivated pacemaker channel of brain. Cell, 93, 717-729.

Satoh, T.O. \& Yamada, M. (2000) A bradycardiac agent ZD7288 blocks the hyperpolarization-activated current $(\mathrm{I}(\mathrm{h}))$ in retinal rod photoreceptors. Neuropharmacology, 39, 1284-1291.

Seeliger, M.W., Grimm, C., Stålberg, F., Friedburg, C., Jaissle, G., Zrenner, E., Guo, H., Remé, C.E., Humphries, P., Hofmann, F., Biel, M., Fariss, R.N., Redmond, T.M. \& Wenzel, A. (2001) New views on RPE65 deficiency: the rod system is the source of vision in a mouse model of Leber congenital amaurosis. Nat. Genet., 29, 70-74.

Seifert, R., Scholten, A., Gauss, R., Mincheva, A., Lichter, P. \& Kaupp, U.B. (1999) Molecular characterization of a slowly gating human hyperpolarization-activated channel predominantly expressed in thalamus, heart, and testis. Proc. Natl Acad. Sci. USA, 96, 9391-9396.

Wachtmeister, L. (1998) Oscillatory potentials in the retina: what do they reveal. Prog. Ret. Eye Res., 17, 485-521.

Wässle, H. \& Boycott, B.B. (1991) Functional architecture of the mammalian retina. Physiol. Rev., 71, 447-480.

Yu, H., Chang, F. \& Cohen, I.S. (1995) Pacemaker current i(f) in adult canine cardiac ventricular myocytes. J. Physiol., 485, 469-483.

Yu, H.-G., Lu, Z., Pan, Z. \& Cohen, I.S. (2004) Tyrosine kinase inhibition differentially regulates heterologously expressed $\mathrm{HCN}$ channels. Pflügers Arch. Eur. J. Physiol., 447, 392-400.

Zolles, G., Klöcker, N., Wenzel, D., Weisser-Thomas, J., Fleischmann, B.K., Roeper, J. \& Fakler, B. (2006) Pacemaking by HCN channels requires interaction with phosphoinositides. Neuron, 52, 1027-1036. 